\title{
Membrane Distillation Provides a Dual Barrier for Coronavirus and Bacteriophage Removal
}

\section{Supporting Information}

\author{
Mukta Hardikar ${ }^{1,2}$, Luisa A. Ikner ${ }^{2,3}$, Varinia Felix ${ }^{1,2}$, Luke K. Presson ${ }^{1,2}$, Andrew B. Rabe ${ }^{2,3}$, Kerri \\ L. Hickenbottom ${ }^{1,2}$, and Andrea Achilli ${ }^{1,2^{*}}$ \\ ${ }^{1}$ Department of Chemical and Environmental Engineering, University of Arizona, Tucson, AZ, \\ 85721, United States \\ ${ }^{2}$ Water and Energy Sustainable Technology (WEST) Center, University of Arizona, Tucson, \\ AZ 85745, United States \\ ${ }^{3}$ Department of Environmental Science, University of Arizona, Tucson, AZ, 85721, United States \\ *Corresponding author \\ Email: achilli@email.arizona.edu (Andrea Achilli) \\ Tel: +1 520 621-6586
}

Environmental Science \& Technology Letters

Number of Pages: 9

Number of Figures: 4

Number of Tables: 3 


\section{$\underline{\text { S1. Propagation of Viral Stocks }}$}

All viruses, host bacteria, and cell lines used in the study were procured from the American Type Culture Collection (ATCC, Manassas, Virginia). Stocks of MS2 (ATCC 15597-B1) and PhiX174 (ATCC 13706-B1) were prepared separately using log-phase host cultures of Escherichia coli (ATCC 15597 and ATCC 13706, respectively) and the double layer agar (DAL) technique. Aliquots of virus $(0.1 \mathrm{~mL})$ containing $5 \times 10^{7}$ plaque-forming units (PFU) were combined with $0.50 \mathrm{~mL}$ of the respective bacterial host within molten top agar tubes $(5 \mathrm{~mL})$ and poured over tryptic soy agar (TSA) plates as a double layer agar overlay. The plates were incubated for $22 \pm 2$ hours at $37^{\circ} \mathrm{C}$. Volumes of sterile Nanopure water $(5 \mathrm{~mL})$ were pipetted onto the cleared host lawns and held at room temperature for 2 hours. The virus suspensions were extracted from the plates and centrifuged for 15 minutes at 3,000 x $\mathrm{g}$ to pellet bacterial debris. The supernatant was passed through a $0.22 \mu \mathrm{m}$ filter to remove remaining bacterial debris. The bacteriophage stock titers were calculated (PFU per $\mathrm{mL}$ ), and stocks were stored at $4{ }^{\circ} \mathrm{C}$ until used in the study. Virus suspensions generated during testing were diluted (1:10) using $0.01 \mathrm{M}$ phosphate-buffered saline (PBS) and plated as described using the DAL technique.

Human coronavirus 229E (HCoV-229E; ATCC VR-740) was propagated using the MRC-5 cell line (ATCC CCL-171). Infected cells were freeze-thawed, and lysates underwent a polyethylene glycol (PEG) extraction $[12 \%(\mathrm{w} / \mathrm{v})$ PEG $(8000 \mathrm{~g} / \mathrm{mol})$ and $0.5 \mathrm{M} \mathrm{NaCl}]$ overnight at $4{ }^{\circ} \mathrm{C}$. The suspension was centrifuged (10,000 x g, 60 minutes) and the virus pellets resuspended in $0.01 \mathrm{M}$ PBS to 5\% of the original suspension volume. Aliquots were stored at $-80^{\circ} \mathrm{C}$ until use in the study. Virus stock and test suspension titers were determined after dilution (1:10) as necessary using $0 \%$ fetal bovine sera in minimal essential media ( $0 \%$ FBS MEM). Dilutions were plated at a minimum of three replicates onto MRC-5 monolayers and incubated for nine days $\left(35^{\circ} \mathrm{C}\right)$ in a $5 \% \mathrm{CO}_{2}$ atmosphere. Wells were scored for cytopathogenic effects and the Most Probable Number (MPN) of viruses was calculated using the U.S. EPA Information Collection Rule MPN Calculator.

Water samples collected during testing were processed immediately. For MS2 and PhiX174, control and feed tank samples were filtered $(0.22 \mu \mathrm{m})$ to reduce levels of background bacteria, diluted (1:10) in 0.01M PBS, and plated with the appropriate log-phase host bacteria as previously described. The plates were incubated for $22 \pm 2$ hours at $37^{\circ} \mathrm{C}$. Mean PFU per $\mathrm{mL}$ values were calculated to enumerate infectious viruses. Distillate samples $(220 \mathrm{~mL})$ were assayed using the single agar layer (SAL) technique by combining $100 \mathrm{~mL}$ of tempered distillate with $100 \mathrm{~mL}$ of $2 \mathrm{X}$ TSA and $10 \mathrm{~mL}$ of the 
respective bacterial host. After swirling to mix, the preparations were poured into Petri plates and allowed to solidify, followed by incubation and determination of PFU per $100 \mathrm{~mL}$. Control and feed solution samples collected during HCoV-229E testing were also filtered as described and diluted using Minimal Essential Medium (no serum). Dilutions were plated onto confluent MRC-5 monolayers in replicates of three. Distillate samples $(220 \mathrm{~mL})$ were concentrated using Centricon Plus-70 centrifugal filter units (EMD Millipore), and equivalent distillate volumes of $50 \mathrm{~mL}$ and $20 \mathrm{~mL}$ were assayed in triplicate using confluent MRC-5 host cell monolayers.

Free chlorine levels $(\mathrm{mg} / \mathrm{mL})$ were determined for all control and test water matrices prior to viral inoculation. The Hach Pocket Colorimeter II and DPD Free Chlorine Powder Pillows were used to measure free chlorine in $10 \mathrm{~mL}$ volumes of water, with levels $\leq 0.02 \mathrm{mg} / \mathrm{L}$ deemed as suitable for use in testing.

\section{$\underline{\text { S2. Virus Stability in Varying Test Water Matrices }}$}

Test solutions were prepared in $1 \mathrm{~L}$ conical flasks and included tap water, ultrapure water, antiscalant solution, synthetic salt solution, reverse osmosis (RO) concentrate without antiscalant, and RO concentrate with antiscalant. The RO concentrate used in this study was collected from an engineeringscale ultrafiltration (UF)-RO system in series with secondary-treated effluent from the Agua Nueva Water Reclamation Facility (Tucson, AZ). At 90\% RO recovery, the conductivity was approximately $5,800 \mu \mathrm{S} / \mathrm{cm}$ and the total organic carbon (TOC) concentration was approximately $30 \mathrm{ppm}$. The average composition and properties of the RO concentrate are shown in Table S1. The selection of salts for the synthetic salt solution and their concentrations were based on the composition of the RO concentrate (Table S1). The antiscalant solution was prepared by adding $175 \mu \mathrm{L} / \mathrm{L}$ of Flocon 125 (BWA Water Additives, Manchester, United Kingdom) to tap water to simulate the concentration of antiscalant used in the engineering-scale UF/RO system. The effect of antiscalant is studied because it is similar to a surfactant and may impact viral integrity resulting in loss of infectivity. The salt solution was prepared by dissolving $\mathrm{NaCl}$ (ACS standard, VWR chemicals, Radnor, PA), $\mathrm{CaSO}_{4}$ (ACS standard, Alfa Aesar, Waltham, MA), $\mathrm{CaCl}_{2}$ (ACS Standard, Fisher Chemical, Waltham, MA), $\mathrm{Na}_{2} \mathrm{SO}_{4}$ (ACS standard, VWR chemicals, Radnor, PA), and $\mathrm{MgSO}_{4}$ (Sigma Aldrich, Saint Louis, MO) in tap water. 
Table S1: Water composition of RO concentrate (ROC) at $90 \%$ RO recovery and salt solution. The ROC values represent the highest achieved concentrations in the RO concentrate.

\begin{tabular}{|l|l|l|l|}
\hline \multicolumn{1}{|c|}{ Parameter } & \multicolumn{1}{c|}{ Units } & \multicolumn{1}{c|}{ ROC } & Salt Solution \\
\hline $\mathrm{pH}$ & - & 7.9 & - \\
\hline Conductivity & $\mathrm{mS} / \mathrm{cm}$ & 5.8 & 9.1 \\
\hline $\mathrm{Cl}$ & $\mathrm{ppm}$ & 1,980 & 1,960 \\
\hline $\mathrm{SO}_{4}$ & $\mathrm{ppm}$ & 2,540 & 2,774 \\
\hline $\mathrm{Na}$ & $\mathrm{ppm}$ & 1,368 & 1,368 \\
\hline $\mathrm{Mg}$ & $\mathrm{ppm}$ & 165 & 165 \\
\hline $\mathrm{K}$ & $\mathrm{ppm}$ & 198 & - \\
\hline $\mathrm{Ca}$ & $\mathrm{ppm}$ & 808 & 808 \\
\hline
\end{tabular}

\section{S3. Bench-top Tests: Water Matrix Selection}

Virus was spiked into each test matrix and mixed for 15 minutes. Samples were taken every hour and analyzed to determine virus concentration. Results are shown in Figure S1. Both MS2 and PhiX174 maintained their initial concentrations in all water matrices for four hours (Figure S1 a and b). Samples for $\mathrm{HCoV}-229 \mathrm{E}$ were collected every two hours (Figure S2) and showed less than 1- $\log _{10}$ reduction over five hours in RO concentrate with antiscalant. These tests ensured there would not be a drastic decline of virus concentration because of components in the feed solution during the membrane distillation (MD) test with RO concentrate and antiscalant as the feed solution and ultrapure water as the distillate. The RO concentrate with antiscalant was thus selected as the feed solution and ultrapure water was selected as the distillate for the MD virus rejection tests. 


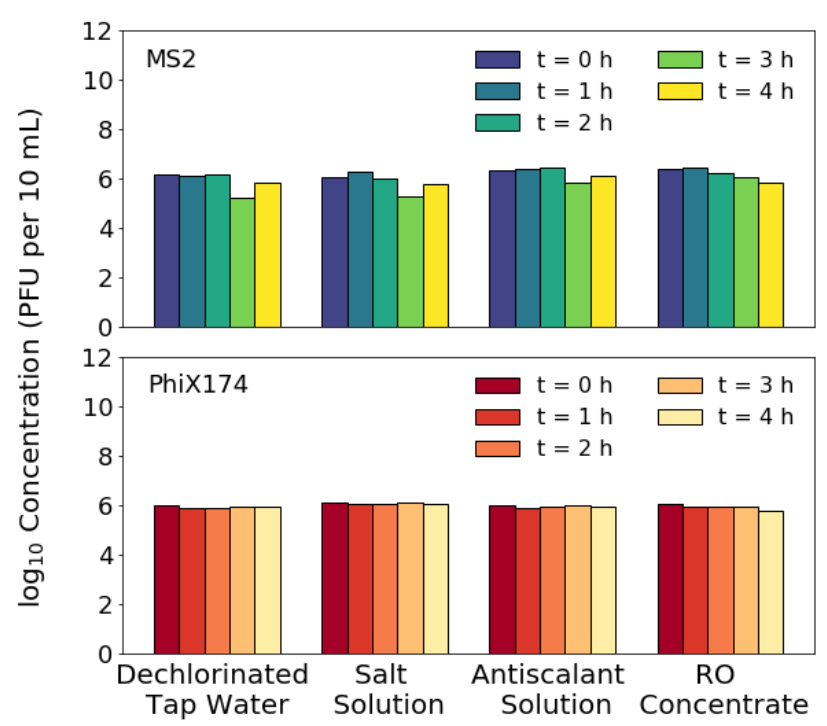

(a)
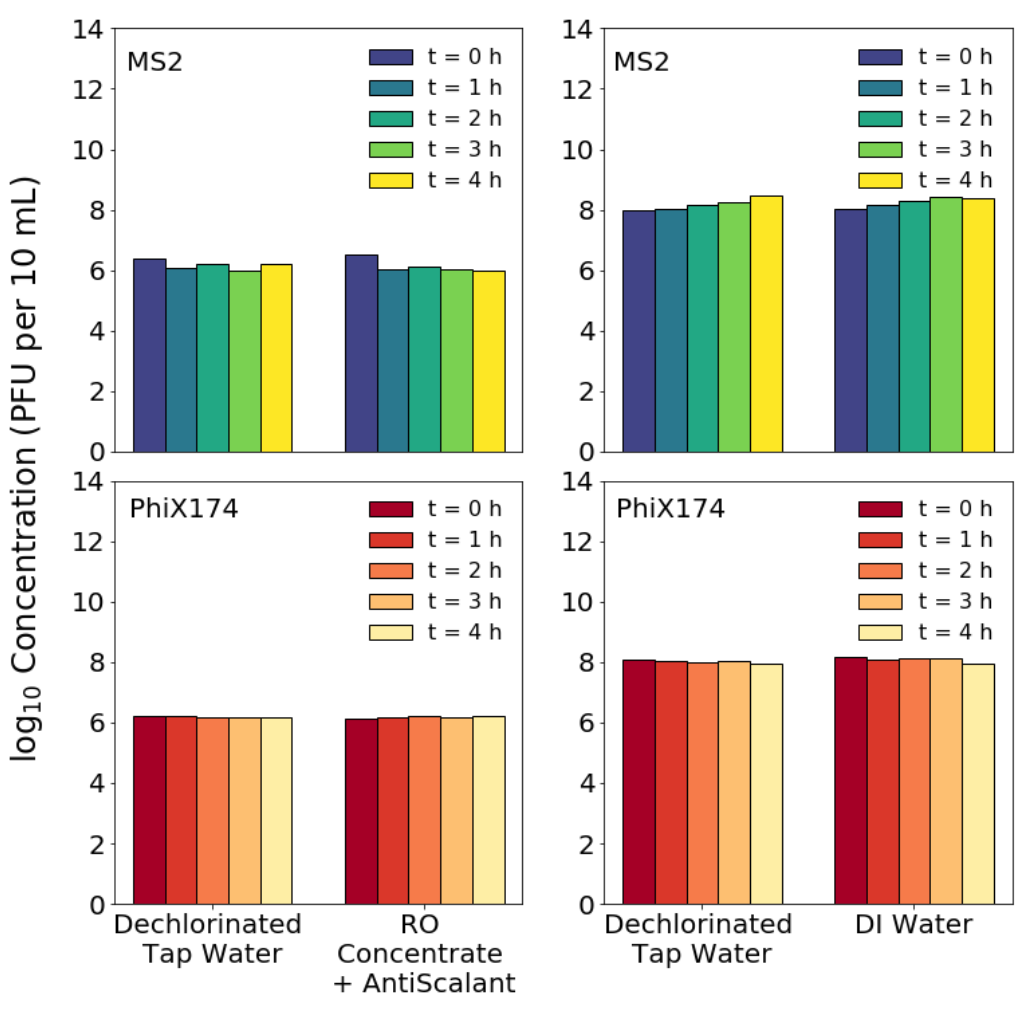

(b)

Figure S1: Water matrix stability tests with both MS2 and PhiX174 showed no reduction in virus concentration in the different water matrices. a) Both viruses were stable in water matrices that represented individual components of RO concentrate (i.e., multi-salt solution, antiscalant solution and other organics in RO concentrate). b) Both viruses also showed no decrease in concentration in RO concentrate with antiscalant and DI water, which were used as the feed solution and the distillate in bench-scale MD tests.

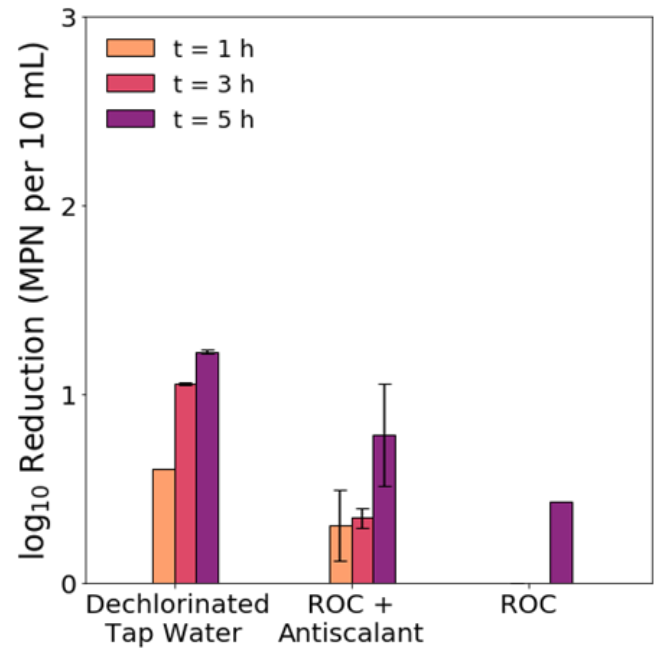

Figure S2: HCoV-229E concentration decreased by less than $1-\log _{10}$ in $\mathrm{RO}$ concentrate in five hours. 


\section{$\underline{\text { S4. Bench-scale Direct Contact Membrane Distillate Set up }}$}

A membrane module of $7.62 \mathrm{~cm}$ length and width and $0.0787 \mathrm{~cm}$ channel height was used. Extruded mesh spacers were placed in the feed and distillate channel of the module to support the membrane and enhance mixing in the flow channels. The schematic for the bench-scale direct contact MD set up is shown in Figure S2. The feed solution is heated using a 1000-W inline heater (Omega, Norwalk, CT) connected through a heat exchanger (Alfa heating, Derwood, MD) and recirculated across one side of the membrane. The distillate flows from the distillate reservoir through a shell and tube heat exchanger (Alfa heating, Derwood, MD) connected to a chiller (Thermo Fisher Scientific, Waltham, MA) into the membrane module and then returns into the reservoir. The feed and distillate solutions are pumped using Micropumps (Cole Parmer, Vernon Hills, IL). The inlet and outlet feed/distillate temperatures and pressures are monitored using K-type temperature sensors and pressure gauges (Cole-Parmer), respectively. The distillate flux is measured as the change in weight of the distillate tank by a weigh scale (Sartorius Lab Instruments GmbH \&Co. Kg, Goettingen, Germany) with $0.1 \mathrm{~g}$ accuracy.

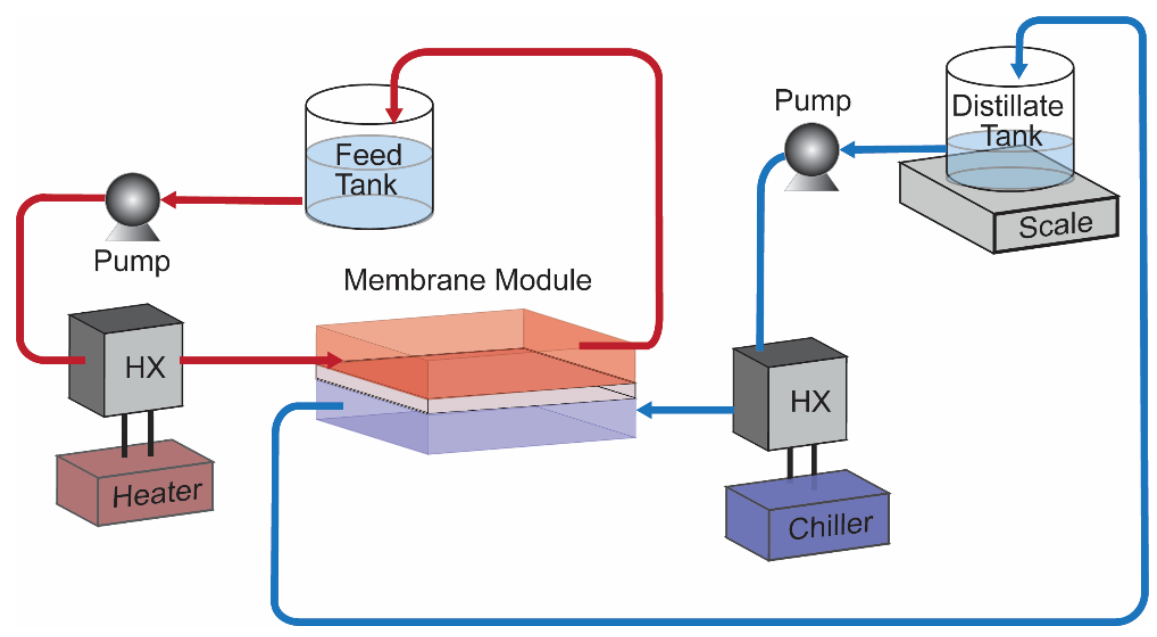

Figure S3: Schematic of MD bench-scale apparatus.

\section{$\underline{\text { S5. Analytical Methods }}$}

All samples were filtered using a $0.45 \mu \mathrm{m}$ glass fiber syringe filter (Tisch Scientific, North Bend, $\mathrm{OH}$ ) before being analyzed. The cation composition in all samples was measured using an Agilent 7800x Series ICP-MS (Agilent, Palo Alto, CA) in helium collision gas mode. ICP-MS filtered samples were acidified with a $2 \%$ solution of $\mathrm{HNO}_{3}$ (Trace metal grade, Fisher Chemical, Waltham, MA). Size 
exclusion chromatography (SEC) was used to determine the average molecular weight (AMW) of organic matter dissolved in samples and was measured using an Agilent 1260 II high performance liquid chromatography (HPLC; Agilent, Palo Alto, CA) with a custom-made 250x20 mm column with Toyopearl HW-50S packing material (Tosoh Bioscience, Tokyo, Japan) followed by a Sievers M9 Portable total organic carbon (TOC) analyzer (Suez Water Technologies and Solutions, Trevose, PA). The HPLC uses a mobile phase consisting of $25 \mathrm{mM} \mathrm{Na}_{3} \mathrm{PO}_{4}$ Sodium Phosphate (Sigma Aldrich, Saint Louis, MO) and 50mM Na $2 \mathrm{SO}_{4}$ (VWR chemicals, Radnor, PA) at a $\mathrm{pH}$ of 6.8 pumped at $1 \mathrm{~mL} / \mathrm{min}$ and an injection volume of $500 \mu \mathrm{L}$. Polyethylene oxide standards (PSS-USA, Amherst, MA) are used to calibrate the SEC analysis. The TOC was measured using a Shimadzu TOC-L CSH Total Organic Carbon Analyzer (Shimadzu Corp., Kyoto, Japan). Samples were prepared for TOC by acidifying 20 $\mathrm{mL}$ of the sample with concentrated $\mathrm{HCl}$ (Fisher Chemical, Waltham, MA).

\section{S6. Bench-scale MD Tests: RO concentrate}

The $\mathrm{Na}^{+}$ion and TOC concentrations in the feed and distillate were determined for samples collected every hour during the bench-scale MD rejection tests using RO concentrate as feed and ultrapure water as distillate. No detectable change in $\mathrm{Na}^{+}$concentration was observed, indicating the membrane pores were not wetted (i.e., pore flow) during the experiments (Table S2). The low $\log _{10}$ rejection of the TOC is consequence of the low TOC feed concentration (approximately $47 \mathrm{mg} / \mathrm{L}$ ) and the relatively high minimum detection limit $(1.0 \mathrm{mg} / \mathrm{L})$. However, no detectable increase in TOC in the distillate was observed. 
Table S2: $\mathrm{Na}^{+}$ion and TOC concentration in the feed and distillate and their respective rejection in one replicate virus rejection test with $\mathrm{RO}$ concentrate as feed solution.

\begin{tabular}{|c|c|c|c|c|}
\hline \multicolumn{5}{|c|}{ Sodium Ion $\left(\mathbf{N a}^{+}\right)$} \\
\hline $\begin{array}{c}\text { Time } \\
(\mathbf{h})\end{array}$ & $\begin{array}{c}\text { Feed } \\
(\mathbf{m g} / \mathbf{L})\end{array}$ & $\begin{array}{c}\text { Distillate } \\
(\mathbf{m g} / \mathbf{L})\end{array}$ & Rejection & $\begin{array}{c}\text { Log }_{10} \\
\text { Rejection }\end{array}$ \\
\hline 0 & 396.213 & $<0.125$ & N.A. & N.A. \\
\hline 1 & 448.898 & $<0.125$ & $>99.970 \%$ & $>3.528$ \\
\hline 2 & 393.888 & $<0.125$ & $>99.970 \%$ & $>3.528$ \\
\hline 3 & 458.01 & $<0.125$ & $>99.971 \%$ & $>3.532$ \\
\hline 4 & 457.318 & $<0.125$ & $>99.973 \%$ & $>3.563$ \\
\hline \multicolumn{5}{|c|}{ Total organic carbon (TOC) } \\
\hline $\begin{array}{c}\text { Time } \\
\text { (h) }\end{array}$ & $\begin{array}{c}\text { Feed } \\
(\mathbf{m g} / \mathrm{L})\end{array}$ & $\begin{array}{c}\text { Distillate } \\
(\mathbf{m g} / \mathrm{L})\end{array}$ & Rejection & $\begin{array}{c}\text { Log } \\
\text { Rejection }\end{array}$ \\
\hline 0 & 47.130 & $<1.0$ & N.A. & N.A. \\
\hline 1 & 47.330 & $<1.0$ & $>97.882 \%$ & $>1.674$ \\
\hline 2 & 45.360 & $<1.0$ & $>97.842 \%$ & $>1.666$ \\
\hline 3 & 45.700 & $<1.0$ & $>97.804 \%$ & $>1.658$ \\
\hline 4 & 46.070 & $<1.0$ & $>97.821 \%$ & $>1.662$ \\
\hline
\end{tabular}

The results of the SEC analysis are shown in Figure S4. The feed SEC analysis shows peaks from left to right for biomolecules, humic acid-like molecules, and lower molecular weight (LMW) dissolved organics. The concentration of the organics in the feed increased over the duration of the experiment as the feed solution becomes concentrated. The distillate showed a peak for LMW organic compounds after 4 hours which indicates their transport into the distillate during the test. Semivolatile organic compounds may have permeated and remained soluble in the distillate due to the low distillate temperature during the experiment $\left(10^{\circ} \mathrm{C}\right)$ and storage $\left(4^{\circ} \mathrm{C}\right)$ of distillate samples. 


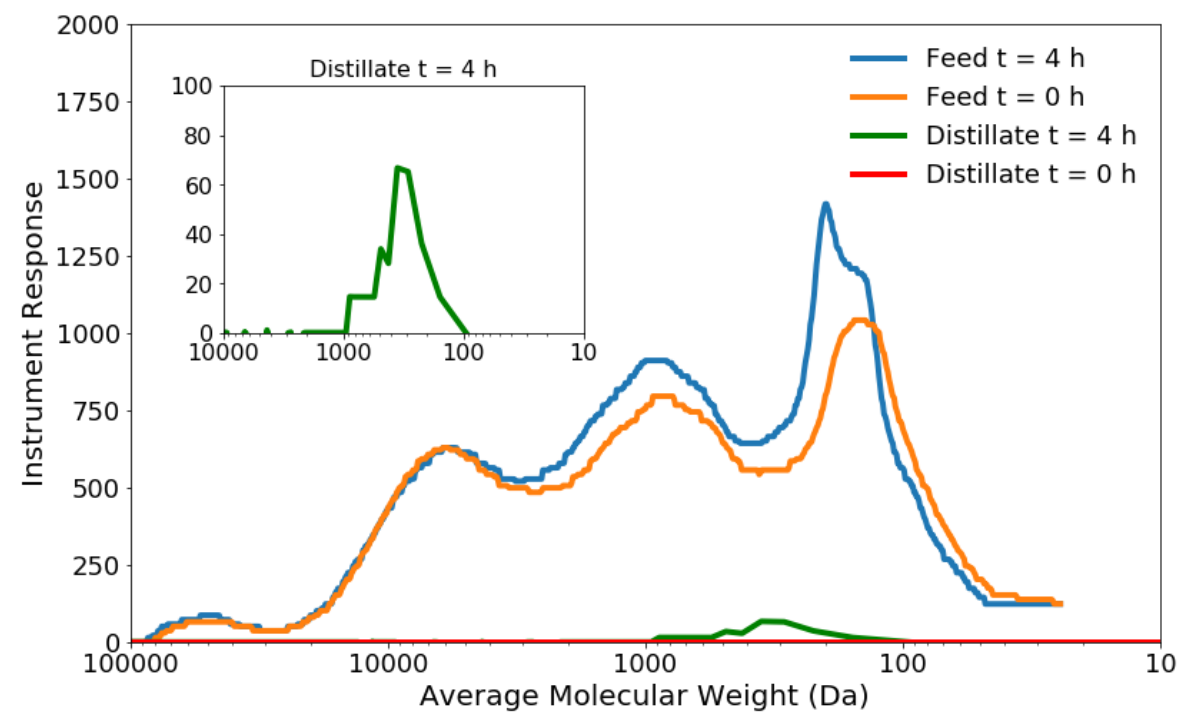

Figure S4: SEC results for samples collected from the feed and distillate tanks at 0 and 4 hours in one replicate virus rejection test with RO concentrate as feed. Lower molecular weight compounds were detected in the distillate tank after 4 hours of the experiment.

Table S3: $\mathrm{Na}^{+}$ion concentration in the feed and distillate solutions and rejection in the high salt concentration membrane rejection test performed after the virus rejection test.

\begin{tabular}{|c|c|c|c|c|}
\hline \multicolumn{5}{|c|}{ Sodium Ion $\left(\mathbf{N a}^{+}\right)$} \\
\hline $\begin{array}{c}\text { Time } \\
(\mathbf{h})\end{array}$ & $\begin{array}{c}\text { Feed } \\
(\mathbf{m g} / \mathbf{L})\end{array}$ & $\begin{array}{c}\text { Distillate } \\
(\mathbf{m g} / \mathbf{L})\end{array}$ & Rejection & $\begin{array}{c}\text { Log }_{10} \\
\text { Rejection }\end{array}$ \\
\hline 0 & 48,284 & 0.613 & N.A. & N.A \\
\hline 1 & 51,820 & 0.332 & $>99.9998 \%$ & $>5.7$ \\
\hline 2 & 56,503 & 0.315 & $>99.9998 \%$ & $>5.7$ \\
\hline 3 & 58,173 & 0.307 & $>99.999945 \%$ & $>6.3$ \\
\hline 4 & 62,134 & 0.384 & $>99.9953 \%$ & $>5.8$ \\
\hline
\end{tabular}

